\title{
ON DEPLOYING VEHICULAR COMMUNICATION AT THE DEVELOPING SEAPORT AND RELATED INNOVATION SUCCESS IMPEDIMENTS
}

\author{
Sanja BAUK ${ }^{1,2,3^{*}}$, Jose Angel LEON CALVO ${ }^{4}$, Anke SCHMEINK ${ }^{5}$, \\ Sadia $\mathrm{AZAM}^{6}$, Rudolf MATHAR \\ 1, 4, 5,7Institute for Theoretical Information Technology, RWTH Aachen University, Germany \\ ${ }^{2}$ Maritime Faculty, University of Montenegro, Montenegro \\ ${ }^{3}$ Dept of Maritime Studies, Faculty of Applied Sciences, Durban University of Technology, South Africa \\ ${ }^{6}$ The Sirindhorn International Thai-German Graduate School of Engineering, \\ King Mongkut's University of Technology North Bangkok, Thailand
}

Received 12 September 2017; revised 13 March 2018, 11 July 2018; accepted 13 September 2018

\begin{abstract}
The paper concerns the employment of a vehicular communication concept for traffic management and safety purposes in a developing seaport environment. A general scenario considering centralized and ad-hoc networks has been analysed, since the requirements for the safety of seaports are similar in terms of reliability and latency. The main enhancement of the proposed model is a communication-based cooperative scheme for improving the safety of workers and optimizing the management of on-port vehicles. The simulation analyses have been realized over the container terminal of the developing Port of Bar (South-East Adriatic Sea, Montenegro). Considering the fact that it operates in transitional conditions, related innovation success impediments have been taken into consideration, as well.
\end{abstract}

Keywords: vehicular communication, seaport, safety, innovation, management, cooperative systems, network planning.

\section{Introduction}

An accelerated development in Information and Communication Technologies (ICT) leads to the emergence of cooperative systems, where vehicles and pedestrians equipped with on-board units can talk to each other and also with the infrastructure through Road-Side-Units (RSU), or dedicated access sites. Such cooperative sensing and controlling systems may exhibit more advanced behaviour compared to vehicles, pedestrians and environments that do not communicate (Wang et al. 2014). The large consortium projects such as: connected vehicles, cooperative vehicle-infrastructure systems, cooperative systems for road safety, strategic platform for intelligent traffic systems, car-2-car, etc., (Alexander et al. 2011; Weiß 2011), have shown the feasibility of Dedicated Short Range Communication (DSRC) technology, which is of key importance for vehicular communication. This technology enables safety and infotainment applications by IEEE $802.11 \mathrm{p}-$ 2010 standard in $5.850 \mathrm{GHz}$ to $5.925 \mathrm{GHz}$ (75 MHz RF), which allows the devices to communicate up to $1000 \mathrm{~m}$ with $32 \mathrm{dBm}$ transmit power (Yan, Rawat 2017).

The main motivation for the deployment of vehicular communication is to have safety-related applications.
By collecting up-to-date information about the status of the road, the driver or pedestrian assistance systems can quickly detect potentially dangerous situations and notify the driver and/or pedestrian about the approaching danger. A relatively small reduction in the driver's and pedestrian's reaction time may potentially avoid the occurrence of an accident (Zhou et al. 2017).

In a seaport environment, we can take a forklift driver as driver; an on-port worker as pedestrian, and a road at the seaport transportation and operational area as road in the vehicular communication system. Some simulation experiments with vehicular communications at the seaport environment have been done with Intelligent Autonomous Vehicles (IAV) at the container terminal (Bahnes et al. 2016). Also, there are some indications that vehicular communication will enter Automated Guided Vehicles (AGV) market (Daniels 2015). The idea of deploying vehicular communication for enhancing occupational safety in a developing seaport environment has been proposed by (Bauk et al. 2017a, 2017b), and it has been extended and deepened within this paper, organized as follows: Section 1 deals with the innovations in general and in

*Corresponding author. E-mail: bsanjaster@gmail.com 
maritime sector, including the adoption of emerging vehicular communication technology; Section 2 concerns impediments in achieving related innovation success in a developing seaport environment, with reference to the Port of Bar (South-East Adriatic Sea); Section 3 describes the vehicular communication system model and related optimization problems, along with the description of the simulation analysis and results in the case of the Port of Bar; and conclusions are reported in last section.

\section{Types of innovations and maritime sector specificity}

In today's advancing technological circumstances, being innovative is of utmost importance for the variety of economic sectors, including maritime industry and seaports. Innovation is the implementation of ideas to create value, and it promises seaports' resilience into the future (Allate 2015). Basically, innovation is described as a historically irreversible change in the way of doing things (Schumpeter 1934). A classic dictionary definition of innovation is the embodiment, combination, or synthesis of knowledge into a new idea, method, or device. Drucker (2006) has defined innovation as a change that creates a new dimension of performance. Narayanan and O'Connor (2010) define innovation as a new idea, method, process, or device that creates a high level of performance for the adopting user. It includes efforts made towards producing economic gain, either by reducing costs, or through increasing income (Sundbo 1998). In addition to commercial innovations motivated by revenue generation or cost-reduction, there are also public innovations motivated by increasing socio-economic welfare (Garcia, Calantone 2002). Even though the exact classification of innovations is rather vague, the deployment of vehicular communication at a seaport with respect to enhancing safety at work can be described as: public, service, incremental, modular, technological, sustaining and responsible innovation.

Public innovation is motivated by increasing socioeconomic welfare, or more precisely, on-port worker's and pedestrians' safety and wellbeing within the analysed scenario.

Service innovation is an intangible method of serving users with a new level of performance. In the context of our study, it means that on-port workers and pedestrians will have a new vehicular communication based service for enhancing occupational safety in the harsh working environment.

Incremental innovation is commonly defined as a refinement or improvement of existing innovation. In the case considered, the innovation based on vehicular communication refines the existing personal protective equipment (safety helmets, shoes and vests), mirrors at the corners at the open storage and warehousing areas in the seaport, horns at hard transportation and manipulative devices, etc., by adding them new, more sophisticated elements.

Modular innovation brings about a significant change in a concept within a component. In the case considered, it is environmental seaport safety management. The links to the other components or (sub)systems remain unchanged and the impact is fairly low.

Technological innovation reflects the application of science and engineering to develop technical applications, or to accomplish a specific technical task. In the examined case, it is about developing a novel technical-engineering application based on vehicular communication for increasing safety and improving environmental management system of the seaport area.

Sustainable innovation improves performance levels of established services and provides incumbent company an opportunity to reinforce its competences. In the seaport environment, it means a positive change in the direction of recognizing the port as safe, green and sustainable one (Maritz et al. 2014).

Responsible innovation promotes the creation of dedicated innovation networks around specific development challenges of the seaport services that involve a cooperative exchange of knowledge, technologies and resources among seaport operators, industrial, technology and research partners (De Martino et al. 2013). In the case analysed it means raising the level of trust and support among employees, seaport authorities, companies and stakeholders.

The transportation sector is the largest industrial research and development investor in Europe, but there are considerable differences in the level of innovation activities carried out by the highly heterogeneous transport subsectors and their specific innovation capacities (Arduino et al. 2013). In particular, there is scattering in assessing the level of innovation success in achieving higher operational efficiency and environmental sustainability at seaports (Arduino et al. 2013; Acciaro et al. 2014). There is also a plethora of needs, economic and institutional factors influencing the process of innovation at seaports (Taneja et al. 2012). Additionally, maritime sector in $\mathrm{Eu}-$ rope is limited to mainly specialist products. For instance, the production of low-value vessels is undertaken outside Europe. In this respect, with the relatively small market of vessels production, the opportunities for recovering the investments targeting innovations in maritime sector, and consequently seaports, are rather limited (Wiesenthal et al. 2015). Furthermore, research, innovations incubation and their diffusion impediments in waterborne transport and seaports are much more emphasized in the so-called developing countries of South-East Europe, which have been functioning in transitional conditions, and which are permanently suffering from the reproduction of economic crisis (Draškovic et al. 2017).

The following section focuses some innovation success impediments versus success factors related to adopting vehicular communication in the developing seaport environment for safety purposes. The model for assessing the success of the seaport-related innovation, presented by Arduino et al. (2013), has been used as a methodological framework. 


\section{Occupational safety innovation with reference to the Port of Bar}

In the case of the considered Port of Bar, with the exception of personal protective equipment (safety helmets, shoes and vests), mirrors at corners, and horns on transportation and manipulative equipment, there is no other safety system based on advanced ICT solutions. In addition, during the recent decades the port has been operating in transitional environment, which is characterized by economic uncertainty, institutional fragility, lack of human capacities and social awareness about innovation, etc. All these and much more have to be taken into consideration while proposing a state of the art technology, as vehicular communication is, for uprising safety management in the invasive and dynamic operational seaport area.

In this context, it should be taken into account that seaports are potentially dangerous places for on-port workers and pedestrians in terms of operational risks connected to loading and unloading operations, port transportation and manipulative equipment, manipulative activities, warehousing, etc. Seaports usually operate in $7 / 24$ regime, in all weather conditions, with multiple employees and contractors carrying out different activities (Roberts, Gray 2013). It is the duty of the employers to preserve the health and safety of workers and to improve occupational safety systems, but unfortunately the accidents at seaports are not a rarity (DfT 2010a, 2010b; Darbra, Casal 2004). The reason for the growing number of accidents is the increase in the seaports' turnover during the past three decades. On the other side, the relatively low turnover at the considered developing seaport (Port of Adria 2018) is in favour of workers' and pedestrians' safety, even though due to the best of our knowledge, there is no official statistical data concerning this issue (Bauk et al. 2018). In any case, permanent improvement in safety measures is an imperative. Towards achieving this, the following sub-section considers some seaport's infra-, supra-structural, institutional and interaction barriers versus success conditions in initiation, development and implementation phases of the safety system based on vehicular communication.

\subsection{Barriers versus success conditions}

The Port of Bar is a moderately developed seaport on the South-East Adriatic Sea, without a strict orientation towards a specific group of cargo. Currently, it consists of four organizational units: Port of Bar, Container terminal and general cargo operator, Maritime operations and IT operators. The port is under the jurisdiction of the Port Authority, located in the town of Kotor. There is also a private company, performing a range of tasks related to the protection of the environment within the port and wider. It has seven technological units for cargo handling: container and general cargo terminal (which is used for the simulation experiments); wood terminal; terminal for grains; bulk cargo terminal; general cargo terminal; liquid cargo terminal, and passenger terminal. In addition to a very complex organizational structure, the port also has a specific ownership structure, where, for the time being, the majority owner is a foreign company.

For such a complex organizational and technological environment, we have proposed a communication matrix between different actors and environmental conditions in the initial, development and implementation phases concerning vehicular communication safety system (Figure 1), in accordance with (Arduino et al. 2013) research work. These communication channels are connected with certain barriers and success conditions.

In the initial phase, we presume the necessity of the existing positive communication between the port authorities and knowledge institutes at infra-, supra-structural, institutional, interaction and human/administrative capacity levels. At this stage, the biggest problems are at the supra-structural and institutional levels. They can be treated as difficult problems. Namely, it might be difficult to provide the funding for RSU, tablets (for forklifts' drivers) and mobile hand-held devices (for on-port workers and pedestrians). Also setting up of a back-end infocommunication system might be a problem, since it commonly requires a costly infrastructure. The development of appropriate legislation (standards) in the domain of port environmental management system and providing funds for the aforementioned supra-structural requirements are prerequisites for achieving success in this initial phase.

In the development phase, additional positive communication with third parties in the port should be established (lobbyists, consultants, agents, etc.), primarily at institutional and interrelation levels. Through the regulation of institutional and interaction conditions, the third parties can be prevented from making obstructions ( $\mathrm{Pa}-$ rola, Maugeri 2013).

In the implementation phase, support should be provided from the external cargo operators in a manner to convince them that these safety measures are in their favour, as well. In such a case, external container cargo operators might provide financial support for the project implementation.

We have set the communication matrix (Figure 1), identifying the barriers and proposing general success conditions based on several in-depth interviews with the seaport top managers, and also based on our intuition and previously acquired experiences in the field.

In the case of the Port of Bar, there is a general orientation towards economic gain, rather than socio-economic welfare. There is certain communication between the port authorities, research institutes and universities, but it is rather week, since the investments from the governmental level in science and education are insufficient, and consequently the research community has a weak influence on companies' innovation incubation and implementation actions. A trend in orienting towards foreign investors and relying on their development politics is prevailing. The last stated is not in favour of innovation success and should be overcome through uprising the responsible entities' awareness of the socio-economic wellbeing and environmental 


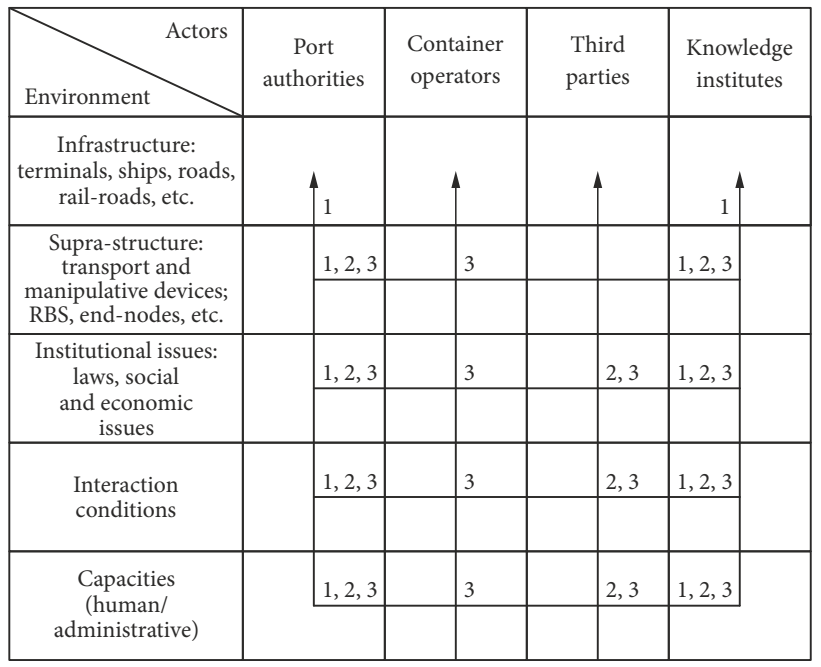

Notes: 1 - initial phase; 2 - development phase; 3 - implementation phase

Figure 1. Actors/institutional environment communication matrix for achieving innovation success (adapted from: Arduino et al. 2013)

protection importance, and through establishing much closer and more effective communication between research institutions, maritime (seaport) industry and business sectors. Thus far, it has been shown that the involvement of foreign investors does not support the economic gain or the socio-economic welfare of the employees and wider local/regional community. All the above stated should be kept in mind by both the inventors (research institutes and universities) and the users (seaport actors and stakeholders) regarding the provision of the fertile soil for innovation, economic growth and social welfare.

\subsection{Innovation success model}

Vehicular communication innovative approach for enhancing occupational safety in a transitional environment of a port might be treated as a rather supply-side innovation. Namely, in the case analysed, the researchers propose the innovation to the seaport's managers, while there is a risk of the managers' misreading of the market and its demand for safe and green ports with zero accidents. A good example of a supply-side approach is the Sony's portable cassette player (the Sony Walkman) on the basis that Sony does not serve markets, it creates them (Kotler, Keller 2015). In this case, the researchers also need to create a market. In fact, in the initial phase of the innovation success, the researchers have to take the role of the marketing managers and recognize the uncovered latent demand. They have to identify and exploit the opportunities (Figure 2). More precisely, they have to offer port authorities a novel safety model based on advanced vehicular communication approach as a complement to the existing personal protective equipment garments, mirrors and horns. Under the assumption of the researchers' success in this first step, new opportunities can appear in time. For instance, on-port workers, pedestrians and forklifts' drivers will most probably prefer their new protective equipment, and they might ask for their additional refinement later on. That way, the researchers could blend the supply- and demand-side approaches into the implementation phase. Upon adopting the innovation, the customers will likely treat the port as a safe and green place. This will raise the customers' confidence in the port services in terms of environmental management, and they might also wish to adopt the same or similar vehicular communication system for occupational safety and production purposes within their industry or business. The afore listed should cause a vivid interplay between the demand- and supplysides within the seaport environment as a primer market place in this case, and beyond. Our assumption was that the port is proactive, so we did not take into consideration its potential reactive behaviour connected to misreading of opportunities and status quo (crossed fields in Figure 2).

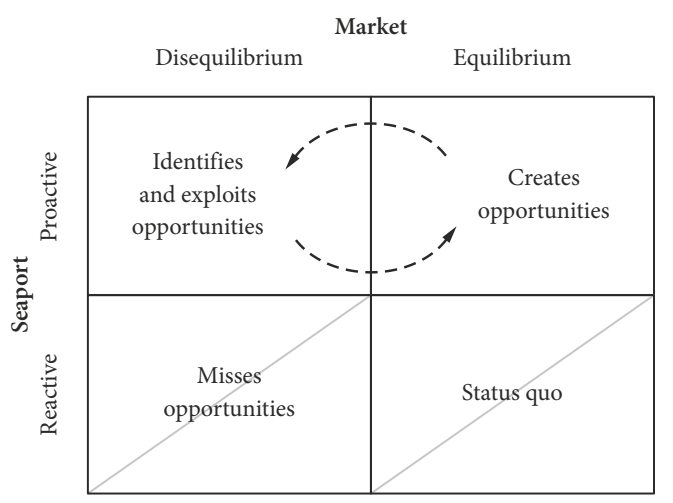

Figure 2. A dynamic model of market creation (adapted from: Darroch, Miles 2010)

Towards innovation success, we can also assume that the innovation initiation, implementation, routinization and development will result in a (positive) repositioning of the seaport in the market and on the customers' perception map. In addition, the considered port might be used as a model to other ports in the region and wider. The above presented dynamic model of the innovation deployment should undoubtedly lead to innovation success. Naturally, it assumes the resolving of the previously identified impediments. It means that the researchers have to persuade the seaport top managers and stakeholders that they need safety and improvements in environmental management system and that vehicular communication is a sound and promising path for achieving it. Accordingly, a vehicular communication safety system model is proposed within the next section.

\section{Proposed vehicular communication model}

Let us consider a set of $N=\{1, \ldots, N\}$ and a set of portworkers and $M=\{1, \ldots, M\}$ forklifts, all of them equipped with mobile devices, enabling Global Positioning System (GPS) signalling and communication. In addition, we consider a set of $K=\{1, \ldots, K\}$ interconnected RSU cov- 
ering the entire port area. It is noteworthy that for the sake of generality, we do not consider any particular communication technology in our proposed scheme. Due to the particularities of seaport areas, we consider concentration areas, denoted as $L=\{1, \ldots, L\}$, where the density of on-port workers and forklifts is higher. Moreover, the environmental information is known by the RSU, i.e., containers' positions, railway infrastructure and (un)load areas, allowing prediction and optimization of traffic and communication load.

Both the on-port workers and the forklifts can communicate among each other (Vehicle-2-Vehicle - V2V) and with a given infrastructure (Vehicle-2-Infrastructure - V2I) through their communication equipment as shown in Figure 3. Due to the restrictive requirements for safety applications in vehicular communications, i.e., high reliability and low latency, the main objective of our simulation is the study of these parameters. The cooperative scheme relies on two complementary concepts: implicit and explicit coordination. The first is established using the on-board equipment of both forklifts and workers allowing them to perform safe manoeuvres. In this level of coordination there are no exchanged messages between the users, but the decisions are based on the local environment of each user. The second level, explicit coordination, consists of using the exchanged messages between the users and infrastructures to optimize and predict future behaviours. Ultimately, the final goal of this proposed framework is to enable the use of autonomous robots to perform the job of human workers. In order to obtain this goal, the cooperative scheme based on communication is of vital importance. Furthermore, our proposed system model includes the idea of concentration areas $L$. These areas have a higher probability of being occupied by forklifts or workers, since these are the areas of loading and unloading. Hence, each worker, $n$, in a concentration area $l$ can be defined as $n_{k}^{l}$, while $\mathrm{k}$ is the RSU, which the worker is connected to. Analogously, the forklifts are denoted as $m_{k}^{l}$. As discussed in the previous section, the seaport under examination has no infrastructure deployed to enable vehicular communications; hence, the first step consists of obtaining the optimal placement of the RSUs. In order to provide a suitable network for safety applications, the area covered by the RSUs has to be the totality

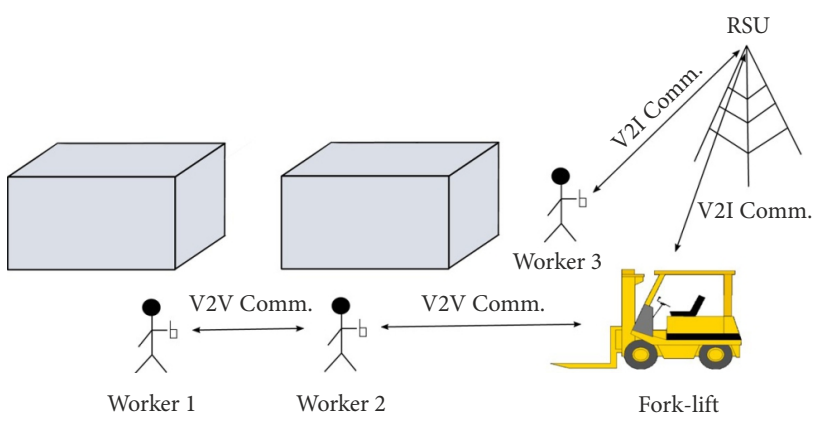

Figure 3. Communication network overview of the seaport area. For this matter, we use the following radio channel model for multi-path environments (Steinbauer et al. 2001):

$$
\begin{aligned}
& h(t, \tau)=\sum_{n=1}^{N} A_{n}(t) \cdot e^{j \cdot \beta_{n}(t)} \cdot \delta(t-\tau) \times \\
& \delta\left(\varphi-\varphi_{n}\right) \cdot \delta\left(\theta-\theta_{n}\right),
\end{aligned}
$$

where: $A_{n}$ is the amplitude for each received path $n ; \beta_{n}$ denotes the phase of the received ray; $\theta$ and $\varphi$ are the angle of arrival in azimuth and elevation plane, respectively.

In order to plan the deployment of the RSUs, we define a constraint:

$$
P_{r e c}(t) \geq P_{t h}
$$

s.t.

$$
P_{\text {rec }}(t)=|h(t, \tau)|^{2} \text {. }
$$

By using this constraint, it is guaranteed that the entire seaport area is covered within a certain received power threshold for all time instant $t$. Moreover, in an environment with several users sharing the same resources and infrastructure, the problem of interference arises. Hence, we define the SIgnal-to-Noise Ratio (SINR) as follows, in order to model the interference and the impact in the communication:

$$
\operatorname{SINR}(t)=\frac{P_{\operatorname{rec}_{n}}(t) \cdot G_{n}}{\sum_{j \in U} P_{j}(t) \cdot G_{j}+\sum_{i \in V} P_{i, n}(t) \cdot G_{i, n} \cdot I_{i, n}+\zeta},
$$

where: $P_{r e c_{n}}(t)$ is the received power as defined in Equation (2b) and $G_{n}$ is the signal gain for each user $n$. The first term in the denominator defines the interference created by collisions, i.e., two users using the same resource block, while the second term is the In-Band Emission Interference (IBEI) produced by the leakage between sub-bands and $\zeta$ is modelled as a random variable. Therefore, the SINR depends on the received signal and the interference value, which is influenced by the number of users, connected simultaneously and varies in time. The set $U$ contains all the workers under the coverage of the same infrastructure sharing the same resources and $V$ defines the set of workers located under the coverage of the infrastructure $\mathrm{k}$ but connected to a different infrastructure. Moreover, since the concentration areas are known in our scenario, we want to maximize the received power in these areas $P_{l}$, by means of an optimal beam-forming as follows:

$$
\begin{aligned}
& \max _{\theta_{i}, \phi_{i}} P_{l}=\left|h(t, \tau)^{H}, w\left(\theta_{i}, \varphi_{i}\right)\right|^{2} \\
& \text { s.t. } \\
& \theta_{i}=\alpha_{l} \\
& \varphi_{i}=\gamma_{l},
\end{aligned}
$$

where: $\alpha_{l}$ and $\gamma_{l}$ are defined in order to cover the desired concentration area $l \in L$ and $w$ is the antenna beamforming based on the Channel State Information (CSI), 
which depends on both angles $\theta_{i}$ and $\varphi_{i}$. The proposed concept of concentration areas $L$ has a double advantage. It enhances the communication signal in the areas with a higher density of users, while at the same time, decreases the interference produced by adjacent cells, since the power in these areas is smaller.

\subsection{Simulation setup}

The simulation experiments related to emerging vehicular communication are done over the container and general cargo terminal at the Port of Bar. This terminal has a quadrilateral form, which can be approximated by a rectangle with dimensions $650 \times 350 \mathrm{~m}$ (Figure 4). The container terminal is located at the 13 pier I of the port and it covers an area of $60000 \mathrm{~m}^{2}$. Wharf length is $330 \mathrm{~m}$ and the depth of the sea is $11 \mathrm{~m}$. The surface of the terminal is divided into zones, and connections for refrigerated containers are also provided. The terminal has an area for disposal of 2635 TEU in the range of the container crane. It has also 13 modular fields with the capacity of 2320 TEU per field. Additionally, the terminal has 6 modular fields for transportation and manipulation operations with $6320 \mathrm{TEU}$ per field. The turnover was 50000 TEU in 2017 (Port of Adria 2018), while the containers handling is realized in direct manipulation with railway wagons or other means of transportation. The general cargo terminal is located at the piers I and II of the Port of Bar, and it is equipped with necessary devices for loading, unloading and manipulating cargo (including forklifts). The length of the operational waterside line is $1370 \mathrm{~m}$. The terminal is equipped with 15 portal cranes with the capacity of $15 \mathrm{t}$ per crane. The number of workers at the port depends on the workload and daily operational plans, and it varies from several workers to $20 \ldots 25 \mathrm{per}$ terminal/shift. Similar simulations have been conducted deploying three base stations and 10 mobile users, i.e., workers and forklifts in total (Bauk et al. 2017a, 2017b) without taking into consideration the interference between adjacent cells and users.

Table 1. Simulation parameters

\begin{tabular}{|l|c|}
\hline \multicolumn{1}{|c|}{ Parameters } & Value \\
\hline Bandwidth & $10 \mathrm{MHz}$ \\
\hline Frequency base station & $2.4 \mathrm{GHz}$ \\
\hline Frequency workers/FL & $5.9 \mathrm{GHz}$ \\
\hline Transmission power & $23 \mathrm{dBm}$ \\
\hline
\end{tabular}

As described in Section 3, the communication scheme has a hybrid nature, therefore, the communication frequency is adapted according to the requirements, i.e., for V2I the used frequency is $2.4 \mathrm{GHz}$, while for V2V the used one is $5.9 \mathrm{GHz}$. Moreover, the rest of the relevant parameters are defined in Table 1. In order to simulate the radio channel model, a combination of a deterministic ray-tracer algorithm (PIROPA) (Schröder et al. 2010) and a stochastic radio channel model (WINNER II) is used (Xu et al. 2011). This approach has been applied success- fully in several scenarios (Calvo et al. 2015), obtaining similar values compared with the real measurements. The main advantage of this combined channel model is the site-specific outcome, i.e., since the ray-tracer algorithm uses as input the real scenario map, the different obstacles and reflectors that interfere with the signal can be accurately modelled. Moreover, due to the high precision of the environmental information, it is possible to obtain a model for the multi path reflections gaining a highly precise radio channel representation (more information about the radio channel model implementation can be found in (Calvo et al. 2015)). The simulation has been performed using a $2.6 \mathrm{GHz}$ Intel Core i5 with $16 \mathrm{~GB}$ of RAM, while the obtained results are presented within the next section.

\subsection{Simulation results}

The simulation scenario is depicted in Figure 4. The workers paths are simulated with a speed in the range of 1.4 to $2.5 \mathrm{~m} / \mathrm{s}$ (blue lines in Figure 4), while the forklifts move at a maximum speed of $6 \mathrm{~m} / \mathrm{s}$ (red lines in Figure 4).

The routes of the workers and the forklifts are predefined and known by the infrastructure and authorities, respectively. Moreover, since the proposed radio channel model has an environment-based component, it is important to know the environment information at any time, i.e., the number and location of all the containers. The situation of the containers shown in Figure 4 is the usual one. Therefore, the complete seaport area has a deterministic behaviour, i.e., the ship arrivals and working areas are planned beforehand, making our approach suitable for this situation.

In Figure 5, the received power at any port location is shown. In this situation, three base stations are deployed at the positions shown in Figure 4 denoted as BS1, BS2 and BS3, covering the entire port area with the power con-

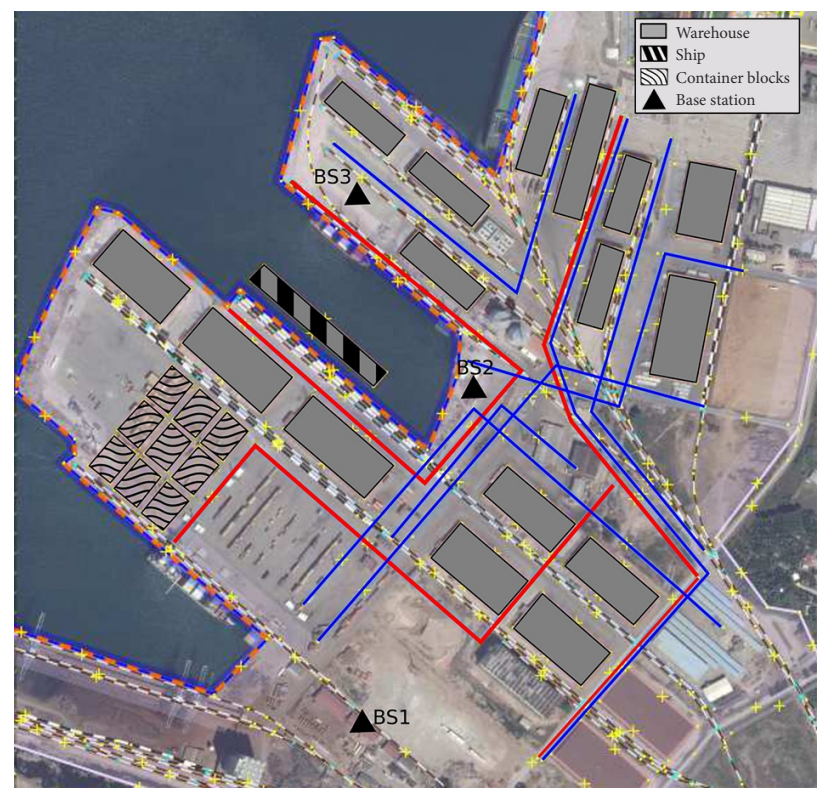

Figure 4. Deployed network and routes at the Port of Bar 
straint defined in Equation (2). It is noteworthy that there are areas, which are shadowed by the containers causing a lower received power. Due to this obstruction, created by different environment elements, the already mentioned idea of concentration areas is useful. The concentration areas are defined next to the container locations as it is displayed in Figure 6 for BS2.

a)

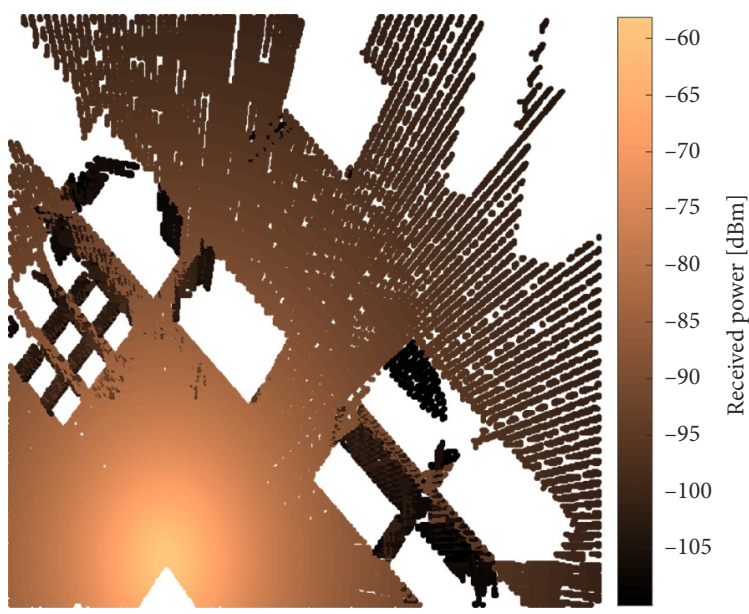

b)

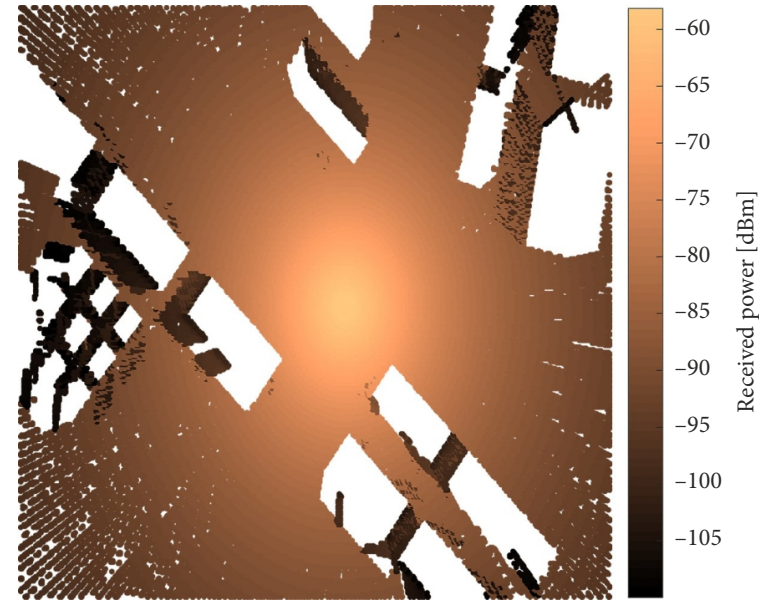

c)

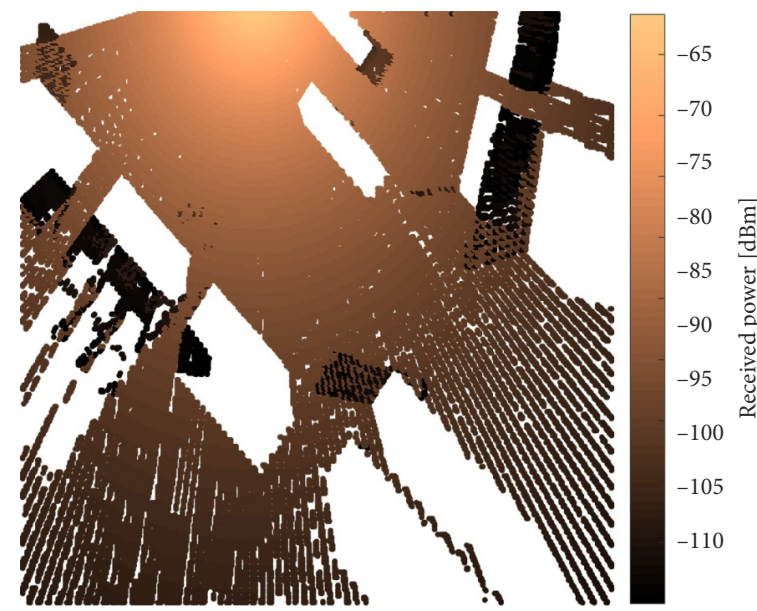

Figure 5. Heat map for three base stations at the Port of Bar: a - BS1; b - BS2; c - BS3

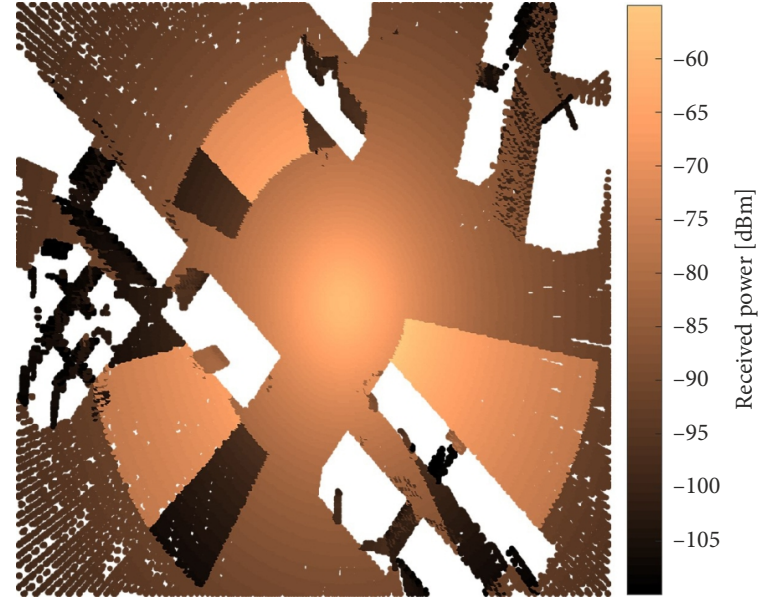

Figure 6. Tri-sector antenna pattern for concentration areas

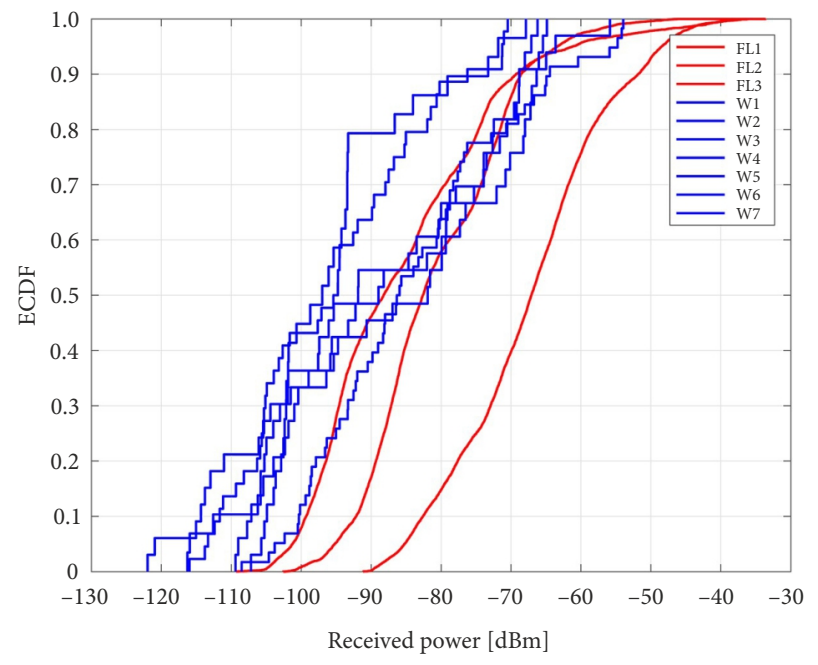

Figure 7. ECDF for V2V communication

Due to this concept of concentration areas, a double goal is achieved: the areas with lower received power are reduced and the areas adjacent to the containers have a higher received power, increasing the reliability of communications. The final parameter to analyse is the communication between workers and forklifts (V2V). For this purpose, we have simulated workers and forklifts on their predefined routes as shown in Figure 4. The results of this simulation are depicted in Figure 7.

The study on the received power has been performed using an Empirical Cumulative Distribution Function (ECDF) in order to show the coverage profile for each path. Since our study works with the samples obtained from the proposed radio channel model, using the ECDF is the most suitable way of representation. The simulation shows that the received power lies in the range of $-130 \mathrm{dBm}$ up to $-30 \mathrm{dBm}$, which creates a feasible and reliable communication scheme. It is noteworthy to mention the higher received power by the forklifts due to the higher altitude of their antennas, creating Loss of Sight (LoS) situations. Moreover, the simulation also takes into consideration the interference defined in Equation (3), due to 
the adjacent cells and the shared resources by several users at the same time. Moreover, considering that our approach keeps the focus on safety, it is critical to investigate the reliability of the communications. For this purpose, the delay, Doppler and angular spread are detailed in Table 2.

It has been shown that the delay for the overall communication scheme is in the range of dozens of $\mu \mathrm{s}$, which is acceptable for safety applications. In addition, both angular and Doppler parameters are useful for the design of the receiver equipment in order to maximize the reliability of the communications.

Table 2. Delay, Doppler and angular parameters

\begin{tabular}{|l|c|c|c|}
\cline { 2 - 4 } \multicolumn{1}{c|}{} & Max & Min & $\begin{array}{c}\text { Standard } \\
\text { deviation }\end{array}$ \\
\hline Delay spread $[\mu \mathrm{s}]$ & 37.358 & 11.135 & 5.637 \\
\hline Doppler spread $[\mathrm{Hz}]$ & 5.345 & -4.849 & 1.871 \\
\hline Angular spread $\left[{ }^{\circ}\right]$ & - & 181.512 & 109.245 \\
\hline
\end{tabular}

\section{Conclusions}

This paper proposes a vehicular communication network model to increase the on-port safety of workers and machinery in the developing seaport environment. The proposed vehicular scheme prioritizes the communication reliability, which is the main aspect in safety applications.

The idea of using vehicular communications for onport safety comes from the similar requirements of both fields, i.e., V2V and Worker-2-Worker (W2W) communication, and also due to the efforts done in the research of vehicular networks in the scope of 5G technology.

The simulations show a feasible network scenario involving communication equipment for on-port workers, pedestrians and machinery, along with the deployment of communication infrastructures. Moreover, the concept of concentration areas, creating a heterogeneous network, has been introduced enhancing the communication scheme and reducing the interferences. Undoubtedly, the technology works, but we cannot neglect the problem of innovation impenitence versus success factors in general and in transitional conditions as considered in the first and the second part of the paper.

Through the forthcoming work in the field, the researches should bare in mind the following: the innovation cannot be restricted to the adoption of new technologies; instead it is to be conceived as a creative use of technology in order to interpret the market or integrate the knowledge. Additionally, the innovation culture can be nurtured on a continuous basis by promoting the creation of dedicated innovation networks around specific development challenges of seaports, involving the exchange of knowledge, technologies and resources among seaport operators, industrial, technology, and research and development partners.

Only those innovations that meet the dynamical seaports actors' demands and the seaport institutional en- vironment stand a chance to succeed. In addition to the above noted, the future research work in this domain should include the analysis of considerably larger emerging and developing seaports of Asia and South America.

\section{References}

Acciaro, M.; Vanelslander, T.; Sys, C.; Ferrari, C.; Roumboutsos, A.; Giuliano, G; Lam, J. S. L.; Kapros, S. 2014. Environmental sustainability in seaports: a framework for successful innovation, Maritime Policy \& Management: The Flagship Journal of International Shipping and Port Research 41(5): 480-500. https://doi.org/10.1080/03088839.2014.932926

Alexander, P; Haley, D.; Grant, A. 2011. Cooperative intelligent transport systems: $5.9-\mathrm{GHz}$ field trials, Proceedings of the IEEE 99(7): 1213-1235.

https://doi.org/10.1109/JPROC.2011.2105230

Allate, B. M. 2015. Shipping management and logistics innovation: key factors for success, International Journal of Management Science and Business Administration 2(1): 50-55. https:// doi.org/10.18775/ijmsba.1849-5664-5419.2014.21.1005

Arduino, G.; Aronietis, R.; Crozet, Y.; Frouws, K.; Ferrari, C.; Guihéry, L.; Kapros, S.; Kourounioti, I.; Laroche, F.; Lambrou, M.; Lloyd, M.; Polydoropoulou, A.; Roumboutsos, A.; Van de Voorde, E.; Vanelslander, T. 2013. How to turn an innovative concept into a success? An application to seaport-related innovation, Research in Transportation Economics 42(1) 97-107. https://doi.org/10.1016/j.retrec.2012.11.002

Bahnes, N.; Kechar, B.; Haffaf, H. 2016. Cooperation between Intelligent Autonomous Vehicles to enhance container terminal operations, Journal of Innovation in Digital Ecosystems 3(1): 22-29. https://doi.org/10.1016/j.jides.2016.05.002

Bauk, S.; Calvo, J. A. L.; Mathar, R.; Schmeink, A. 2017a. V2P/I communication for increasing occupational safety at a seaport, in 2017 International Symposium ELMAR, 18-20 September 2017, Zadar, Croatia, 79-82.

https://doi.org/10.23919/ELMAR.2017.8124439

Bauk, S.; Calvo, J. A. L.; Schmeink, A.; Mathar, R. 2017b. Enhancing on port safety by vehicular communication approach: port of Bar (Montenegro) case study, in 2017 6th Mediterranean Conference on Embedded Computing (MECO), 11-15 June 2017, Bar, Montenegro, 1-4. https://doi.org/10.1109/MECO.2017.7977231

Bauk, S.; Schmeink, A.; Colomer, J. 2018. An RFID model for improving workers' safety at the seaport in transitional environment, Transport 33(2): 353-363. https://doi.org/10.3846/16484142.2016.1233512

Calvo, J. A. L.; Schröder, F.; Xu, X.; Mathar, R. 2015. A validation using measurement data of a radio channel model with geographical information, in 2015 9th European Conference on Antennas and Propagation (EuCAP), 13-17 April 2015, Lisbon, Portugal, 1-4.

Daniels, M. 2015. VDL towards new generation AGV. VDL Containersystemen. Available from Internet: https://www.vdlautomatedvehicles.com/news

Darbra, R.-M.; Casal, J. 2004. Historical analysis of accidents in seaports, Safety Science 42(2) 85-98.

https://doi.org/10.1016/S0925-7535(03)00002-X

Darroch, J.; Miles, M. P. 2010. Sources of innovation, in V. K. Narayanan, G. C. O'Connor (Eds.). Encyclopedia of Technology and Innovation Management, 97-103.

De Martino, M.; Errichiello, L.; Marasco, A.; Morvillo, A. 2013. Logistics innovation in Seaports: an inter-organizational 
perspective, Research in Transportation Business \& Management 8: 123-133. https://doi.org/10.1016/j.rtbm.2013.05.001

DfT. 2010a. Port Employment and Accident Rates Survey: 2009/10. Department for Transport (DfT), UK. 5 p. Available from Internet: https://assets.publishing.service.gov.uk/government/uploads/system/uploads/attachment_data/file/729976/port-employment-and-accident-rates-statistical_release-2009-10.pdf

DfT. 2010b. Transport Statistics Bulletin: Port Employment and Accident Rates 2009/10. Department for Transport (DfT), UK. 104 p. Available from Internet: https://assets.publishing. service.gov.uk/government/uploads/system/uploads/attachment_data/file/729977/port-employment-and-accident-ratesfull-report-2009-10.pdf

Draškovic, M.; Bauk, S.; Streimikiene, D.; Draskovic, V. 2017. Testing the level of alternative institutions as a slowdown factor of economic development: the case of Montenegro, Amfiteatru Economic 19(45): 477-492.

Drucker, P. F. 2006. Innovation and Entrepreneurship. Harper Business. 288 p.

Garcia, R.; Calantone, R. 2002. A critical look at technological innovation typology and innovativeness terminology: a literature review, Journal of Product Innovation Management 19(2): 110-132. https://doi.org/10.1016/S0737-6782(01)00132-1

IEEE 802.11p-2010. IEEE Standard for Information Technology - Local and Metropolitan Area Networks - Specific Requirements - Part 11: Wireless LAN Medium Access Control (MAC) and Physical Layer (PHY) Specifications Amendment 6: Wireless Access in Vehicular Environments. https://doi.org/10.1109/IEEESTD.2010.5514475

Kotler, P. T.; Keller, K. L. 2015. Marketing Management. 15th edition. Pearson. 832 p.

Maritz, A.; Shieh, C. J.; Yeh, S. P. 2014. Innovation and success factors in the construction of green ports, Journal of Environmental Protection and Ecology 15(3A): 1255-1263.

Narayanan, V. K.; O'Connor, G. C. 2010. Encyclopedia of Technology and Innovation Management. Wiley. $562 \mathrm{p}$.

Parola, F.; Maugeri, S. 2013. Origin and taxonomy of conflicts in seaports: towards a research agenda, Research in Transportation Business \& Management 8: 114-122. https://doi.org/10.1016/j.rtbm.2013.07.005

Port of Adria. 2018. Port of Adria - Catalogue 2018. Commercial sector (Port of Adria), Bar, Montenegro. $16 \mathrm{p}$.

Roberts, B.; Gray, M. 2013. Improving pedestrian safety in container ports and terminals, Port Technology 59: 40-42.

Schröder, F.; Reyer, M.; Mathar, R. 2010. Fast radio wave propagation prediction by heterogeneous parallel architectures with incoherent memory, in WFMN09: Wave Propagation and Scattering in Communication, Microwave Systems and Navigation: Conference Proceedings, 25-27 November 2009, Chemnitz, Germany, 89-93.

Schumpeter, J. A. 1934. The Theory of Economic Development: An Inquiry into Profits, Capital, Credit, Interest, and the Business Cycle. Harvard University Press. 255 p.

Steinbauer, M.; Molisch, A. F.; Bonek, E. 2001. The double-directional radio channel, IEEE Antennas and Propagation Magazine 43(4): 51-63. https://doi.org/10.1109/74.951559

Sundbo, J. 1998. The Theory of Innovation: Entrepreneurs, Technology and Strategy. Edward Elgar Publishing. 232 p.

Taneja, P.; Van Schuylenburg, M.; Vellinga, T. 2012. Ports and innovation, in Two-day International Conference "Key Developments in the Port and Maritime Sector": WCTRS - Special Interest Group 2, 21-22 May 2012, Antwerp, Belgium, 1-14.

Wang, M.; Daamen, W; Hoogendoorn, S.P.; Van Arem, B. 2014. Rolling horizon control framework for driver assistance sys- tems. Part II: cooperative sensing and cooperative control, Transportation Research Part C: Emerging Technologies 40: 290-311. https://doi.org/10.1016/j.trc.2013.11.024

Weiß, C. 2011. V2X communication in Europe - from research projects towards standardization and field testing of vehicle communication technology, Computer Networks 55(14): 3103-3119. https://doi.org/10.1016/j.comnet.2011.03.016

Wiesenthal, T.; Condeço-Melhorado, A.; G. Leduc, G. 2015. Innovation in the European transport sector: a review, Transport Policy 42: 86-93. https://doi.org/10.1016/j.tranpol.2015.05.003

Xu, X.; Reyer, M.; Schröder, F.; Engels, A.; Mathar, R. 2011. A semi-stochastic radio propagation model for wireless MIMO channels, in 2011 8th International Symposium on Wireless Communication Systems, 6-9 November 2011, Aachen, Germany, 619-623. https://doi.org/10.1109/ISWCS.2011.6125429

Yan, G.; Rawat, D. B. 2017. Vehicle-to-vehicle connectivity analysis for vehicular ad-hoc networks, Ad Hoc Networks 58: 25-35. https://doi.org/10.1016/j.adhoc.2016.11.017

Zhou, H.; Xu, S.; Ren, D.; Huang, C.; Zhang, H. 2017. Analysis of event-driven warning message propagation in vehicular ad hoc networks, Ad Hoc Networks 55: 87-96. https://doi.org/10.1016/j.adhoc.2016.09.018 